\title{
Mirror Grinding of Optical Glass by EPD Pellets
}

\author{
Hideo SHIBUTANI ${ }^{1}$, Jun-ichi IKENO ${ }^{2}$ and Akihiko SUZUKI \\ 'Graduate School of Science and Engineering, Saitama University, \\ 255 Shimo-Okubo, Sakura-ku, Saitama City, Saitama 338-8570, Japan, Shibutani@mech.saitama-u.ac.jp \\ ${ }^{2}$ Graduate School of Science and Engineering, Saitama University, ikeno@mech.saitama-u.ac.jp \\ ${ }^{3}$ Graduate School of Science and Engineering, Saitama University, akihiko_suzuki@mech.saitama-u.ac.jp
}

\begin{abstract}
:
Mirror grinding wheels composed of a cerium oxide abrasive and sodium alginate binding-agent were developed using electrophoretic deposition phenomenon. And disk-shaped optical glass samples with a diameter of 3 inches were ground on an ultra-precise surface grinder. As the results, the mirror surface was obtained in a few minutes and the roughness was $1 \mathrm{nmRa}$ and $9 \mathrm{nmRz}$. This grinding technique have possibilities of high-speed mirror grinding for an optical glass.
\end{abstract}

Keywords: Mirror grinding, Optical glass, Surface roughness, EPD pellet

\section{Introduction}

With the increasing production of digital consumer electronics such as personal computer, portable music player, digital still cameras, glass parts like an optical lens and a platter for hard disk drive are in great demand. These parts need an ultra smooth surface and finished by polishing with loose abrasives. But, polishing process is real slow and time-consuming. Solving these problems, mirror grinding technique is very promising.

We have been working on the mirror grinding wheel for silicon wafers ${ }^{(1)-(3)}$. In this study, mirror grinding wheels for the optical-glass were fabricated and the grinding tests were carried out. Purpose of this study is to investigate the feasibility of high-speed mirror grinding of an optical glass.

\section{Mirror Grinding Wheel}

\subsection{Fabrication process}

Fine particles are negatively charged in an alkaline solution in which they get an electric double layer so that they are dispersed homogeneously in the solution due to the repulsion force acting between the particles. When an electric field is applied, the particles are attached to an anode electrode and deposit on it, which is called electrophoretic deposition phenomenon.

The phenomenon is effective for the fabrication of fine abrasive pellet which is called EPD pellet. In this study, fine cerium oxide was used as abrasives for EPD pellet because it is generally using in a polishing of optical glass. When the fine abrasives deposited on an anode and became dry, the outer surface of the deposition layer was cracked. Thus it is necessary to include a bonding agent in EPD pellet in order to use the pellet as a grinding wheel.

Sodium alginate, one of the hydrophilic electrolytes, was use as the bonding agent. The polymers adhere to each of fine particles and form a hydrophilic colloid as show in Fig. 1. Consequently, electrophoretic deposition of the fine abrasives, which wrapped by bonding agents, occurs around an anode.

The fabrication process was as follows.

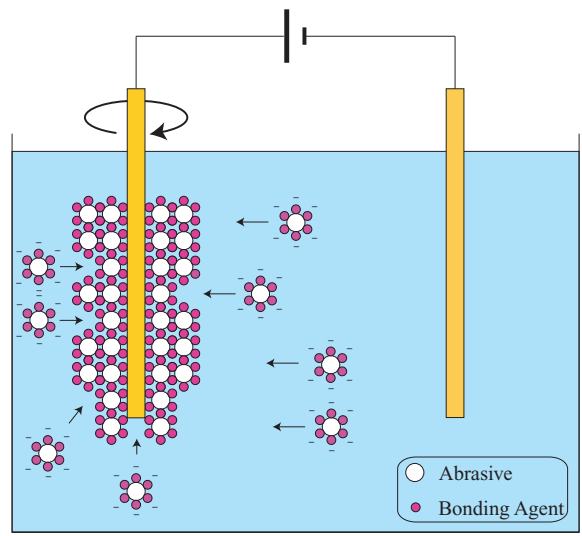

Fig.1 Fabrication of fine abrasive pellet applying electrophoretic deposition 
1. Mix fine cerium oxide abrasives, sodium alginate and pure water uniformly in a vessel.

2. Apply to DC power in the above mixture for forming the deposition layer by electrophoretic deposition.

3. Cutting the deposition layer to suitable size.

4. Dry it more than $24 \mathrm{~h}$ at room temperature.

\subsection{Characteristic of cerium oxide EPD pellet}

Optical glass polishing with cerium oxide abrasives are generally done in a wet condition. But, EPD grinding for the silicon wafer is done in a dry conditions. Therefor, characteristic of cerium oxide EPD pellet in the wet conditions. In this study, swelling characteristic when there are waterdrop on the EPD pellet and vickers hardness when the EPD pellet was soaked in water was investigated.

EPD pellet was sudden expanded just after drop waterdrop of $0.2 \mathrm{cc}$ and swelling reached about $60 \mu \mathrm{m}$ as shown in Fig.2, and vickers hardness was decrease with soak time as show in Fig.3. This result shows that wet grinding with EPD pellet is difficult because of there characteristics. Therefore, water mist spray as a grinding fluid was attempted to mirror grinding of optical glass with cerium oxide EPD pellet.

\section{EPD Grinding Test}

Grinding test of optical glass with EPD pellet, EPD grinding, was carried out using a precision vertical surface grinder. After EPD grinding, observation of the ground surface, the surface roughness were investigated.

Precision vertical surface grinding machine (JTEKT : SG-30) and set up for EPD grinding were shown in Fig.4. The wheel spindle was held by a hydrostatic bearing. Cup-type EPD wheel, which its diameter is $200 \mathrm{~mm}$ and adhered with 22 pellets as shown in Fig. 5, was mounted on the bottom of the spindle.

$\phi 3$ inches optical glass wafer, B270 soda glass, with both polished were prepared and one side was ground by a conventional diamond wheel (\#2000) before EPD grinding. And these wafers were mounted on the rotary table with the $\phi 3$ inches ceramic vacuum chuck held by hydrostatic bearing.

The grinding condition was shown in Table 1. The wheel rotated at $1000 \mathrm{rpm}$, the work at $30 \mathrm{rpm}$, the cutting speed was $10 \mu \mathrm{m} / \mathrm{min}$, the depth of cut was $200 \mu \mathrm{m}$ and an

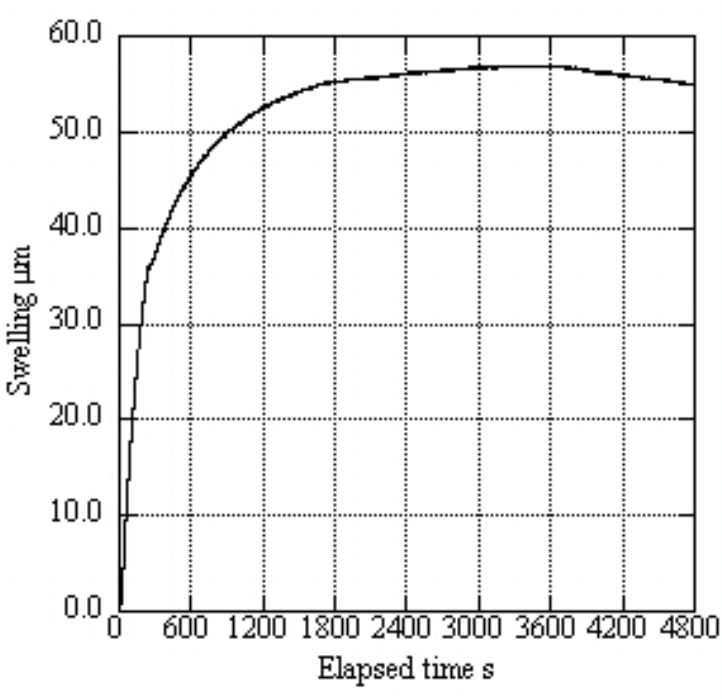

Fig.2 Swelling characteristic of cerium oxide EPD pellet

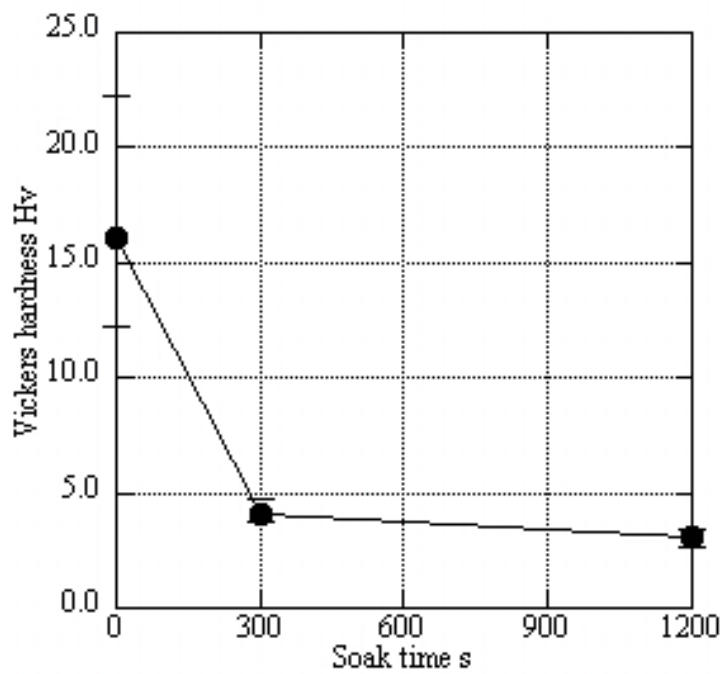

Fig.3 softening characteristic of cerium oxide EPD pellet

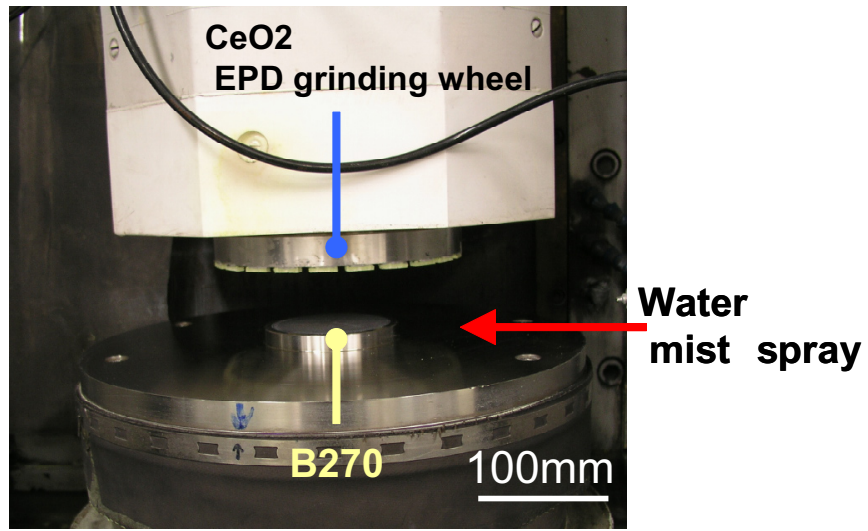

Fig.4 Ultra precision vertical surface grinder and Set up for EPD grinding 
infeed grinding was carried out with water mist spray.

\section{Result and Discussion}

In this study, grinding conditions ware configured that EPD pellet and optical glass were contacted when grinding time was $600 \mathrm{~s}$. But, they were contacted grinding time was about $120 \mathrm{~s}$, and after that, grinding force was increased, an exponential increase was found grinding time was about 180s as shown in Fig.6. Then, infeed motion was forced stopped and observation of ground surface was carried out.

Fig. 7 show appearance of the optical glass wafer after EPD grinding. The wafer before EPD grinding resembled frosted glass in appearance because of grinding marks by a diamond wheel. But after EPD grinding, ground surface had a clear appearance and no scratch marks were also

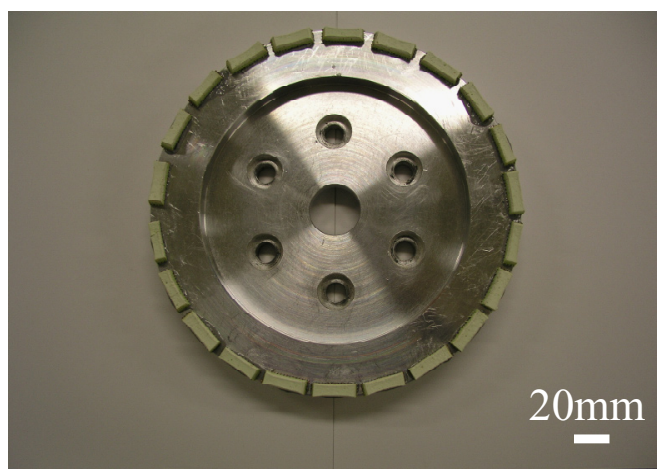

found. But, there were some salient area in the roughness curve as shown in fig. 8. This result shows that there ware adhesion substances on the ground surface, but mirror surface of $9 \mathrm{nmRz}$ was obtained in a short time. This grinding technique have possibilities of high-speed mirror grinding for optical glass.

In this grinding technique, it was considered that the exponential increase of grinding force as shown in fig. 6 was very important phenomenon.

Next grinding test, infeed motion was forced stop before the exponential increase of grinding force was appeared, then the ground surface was observed. Fig. 9 and Fig.10 show the result. This result shows that any adhesion substances on the ground surface was found, but mirror surface was not obtained. This results shows that it is necessary to control and keep suitable grinding force to realize the high-speed mirror grinding of the optical glass.

Table 1 EPD grinding condition

\begin{tabular}{|l|l|}
\hline Wheel rotation & $1000 \mathrm{~min}^{-1}$ \\
\hline Work rotation & $30 \mathrm{~min}^{-1}$ \\
\hline Infeed rate & $1 \mathrm{um} \mathrm{min}^{-1}$ \\
\hline Total depth of cut & $20 \mu \mathrm{m}$ \\
\hline Spark out & $2 \mathrm{~min}$ \\
\hline Coolant & Water mist spray \\
\hline
\end{tabular}

Fig.5 Cup-type EPD wheel

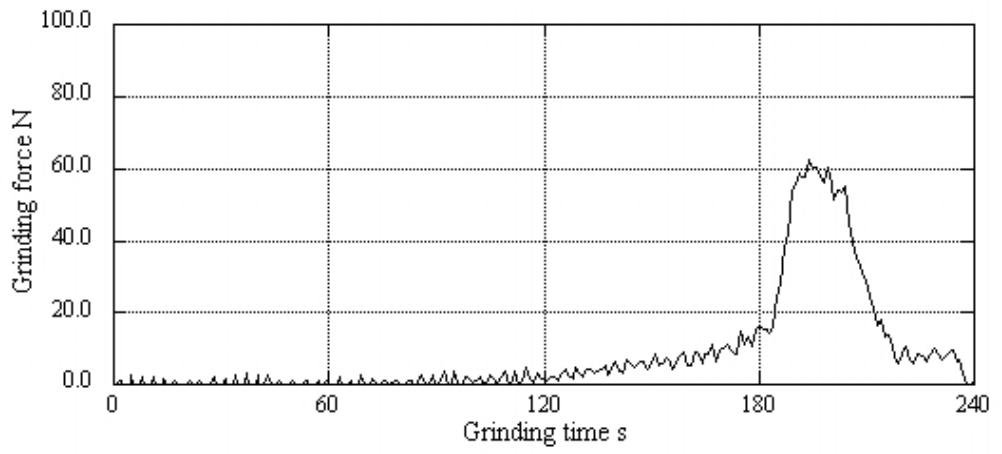

Fig.6 Grinding fourcd during EPD grinding with water mist spray.

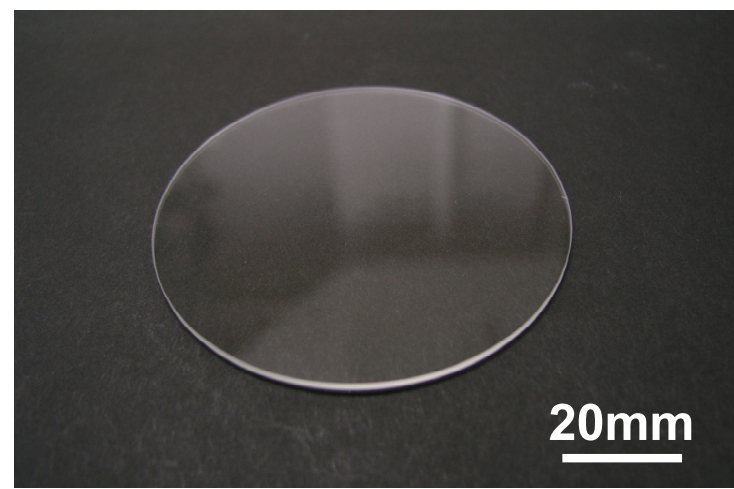

Fig.7 Appearance of ground surface. 


\section{Conclusions}

In this study, mirror grinding wheel, EPD pellet, was fabricated and applied mirror grinding of optical glass.

1. Water mist spray technique was effective for mirror grinding of optical glass with cerium oxide EPD pellets.

2. Mirror surface of $9 \mathrm{nmRz}$ was obtained in a short time(about 2min).

3. This grinding technique have possibilities of highspeed mirror grinding for optical glass.

\section{References}

[1] Fuwa N., Shibutani H., Horiuchi O., Suzuki H. and Ikeno J., 2001, Proc. of the Forth International Symposium on Advances in Abrasive Technology, Korea, Vol. 1, pp.295-302.

[2] Fukazawa T., Fuwa N., Ikeno J.,Shibutani H., Horiuchi O. and Suzuki H., 2001, Proc. $10^{\text {th }}$ ICPE, Japan, Vol.1, pp.366-370.

[3] Shibutani H., Ikeno J., Horiuchi O. and Yano K., 1998, Proc. $9^{\text {th }}$ ICPE, Japan, Vol. 1, pp.98-102.

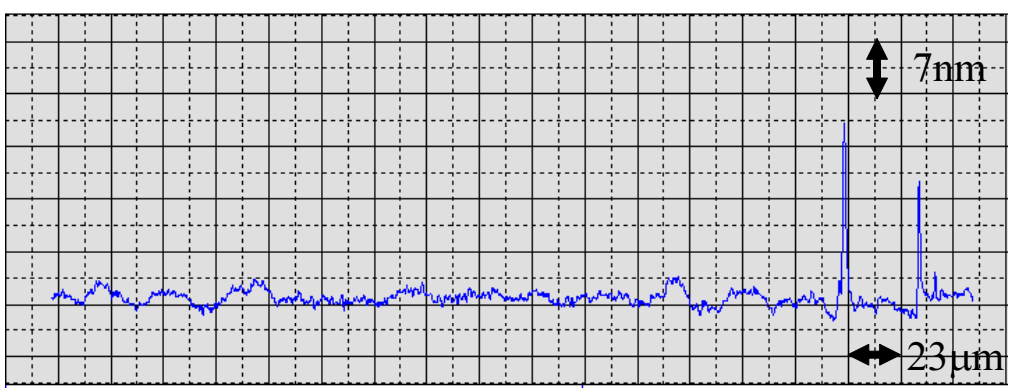

Fig. 8 Surface roughness of ground surface

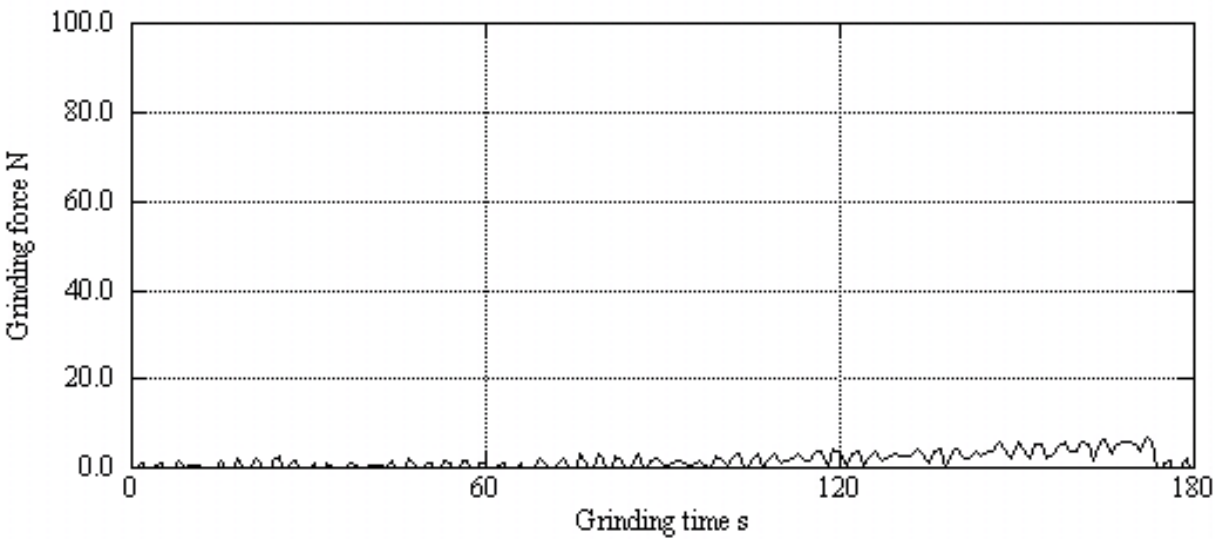

Fig.9 Grinding forcd in case of forced stop

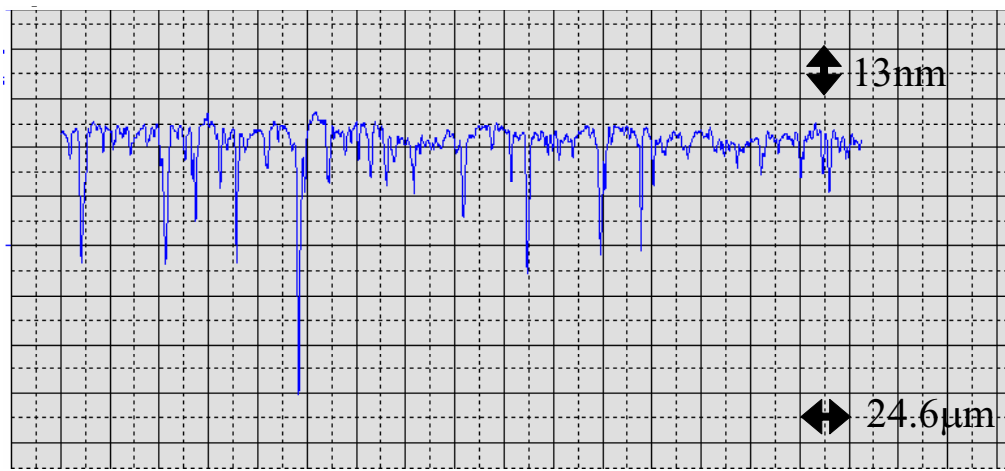

Fig.10 Ground surface roughness in case of forced stop 